\title{
Variability in the Canary Islands Area of Filament-Eddy Exchanges
}

\author{
Eric D. Barton ${ }^{1 *}$, Javier Arístegui ${ }^{2}$, Paul Tett ${ }^{3}$, Eleuteria Navarro Pérez ${ }^{1}$ \\ ${ }^{1}$ School of Ocean Sciences, University of Wales, Bangor, UK \\ ${ }^{2}$ Facultad de Ciencias del Mar, Universidad de Las Palmas de Gran Canaria, Spain \\ ${ }^{3}$ School of Life Sciences, Napier University, Edinburgh, UK
}

\begin{abstract}
:
The physical background to a suite of biological studies carried out in the Canary Islands upwelling region is presented. The area is unique in that the coastal transition zone is spanned by an archipelago of islands that shed mesoscale eddies of diameter 50-100 km into the alongshore flow. A recurrent filament and eddy system was sampled intensively to study the changing properties of waters as they are advected towards the open ocean in the filament and to investigate the exchanges between filament and eddies. The system was more complex than previously revealed. In early August, a single filament extended offshore from near Cape Juby. Two weeks later, a second filament had developed slightly farther north and extended offshore to merge with the first at $\sim 100 \mathrm{~km}$ offshore. The merged filament was entrained around a recurrent, topographically trapped cyclonic eddy and interacted with transient cyclonic and anticyclonic eddies shed from the island of Gran Canaria. Between the two filaments and the coast, a pair of counter-rotating eddies re-circulated water parcels for several weeks. Surface layer drifters cycled around this near-shore recirculation several times before following convoluted paths that demonstrate significant exchange between continental shelf and open ocean waters.
\end{abstract}

Keywords:

Upwelling Eddies Mixing Islands Jets Filaments

Africa Canary Islands Cape Juby

*e.d.barton@bangor.ac.uk

UWB School of Ocean Sciences

Menai Bridge

Anglesey LL59 5AB

UK 


\section{Contents}

1. Introduction

2. Methods

3. Results

3.1. Winds

3.2. Surface structure

3.3. Long line

3.4. Filament sections

3.5. Velocity field

3.6. Drifter trajectories

3.7. TS properties of the filaments

4. Discussion

Acknowledgements

References 


\section{Introduction}

The Canary Current is unique amongst the subtropical eastern boundary currents in that it flows through an archipelago of islands extending from near coast to open ocean. Hierro and La Palma are the islands farthest offshore, located some $500 \mathrm{~km}$ from the African coast, while Fuerteventura and Lanzarote are only $94 \mathrm{~km}$ offshore. Incident flow of both the Canary Current and the Trade winds is disturbed by the abrupt topography of the islands (Fig. 1) to produce a significant downstream wake. Shedding of eddies from the islands results in mesoscale turbulence that interacts with the African shelf region to draw out filaments of cooler, upwelled water high in organic matter that may extend up to several hundred kilometers offshore (Arístegui, Tett, Hernández-Guerra, Basterretxea, Montero, Wild et al., 1997). Perturbations of the flow appear strongest in summer, but sampling has been sparse in other seasons. Arístegui, Sangrá, Hernández-Leon, Cantón, Hernández-Guerra \& Kerling (1994) documented eddies spun off Gran Canaria in March 1991, June 1990 and OctoberNovember 1991. Persistent, strong Trade winds have been suggested as a contributor to eddy production observed in June 1998 (Basterretxea, Barton, Tett, Sangrá, Navarro-Pérez \& Arístegui 2002), July and August 1995 (Barton, Basterretxea, Flament, Mitchelson-Jacob, Jones, Arístegui et al., 2000) and August 1993 (Barton, Arístegui, Tett, Cantón, García-Braun, Hernández-León et al., 1998). Even during periods of weaker relaxed winds, however, eddies have been observed (Rodríguez, Hernández-Leon \& Barton, 1999), suggesting they may arise from current flow disturbance. Remote sensing of the region has defined the seasonal cycle of upwelling (Van Camp, Nykjaer, Mittelstaedt \& Schlittenhardt, 1990) and major features of upwelling filament production (Nykjaer \&Van Camp, 1994) but has not furnished a census of eddy formation or robust information on their interaction with the coastal upwelling.

In this paper, we present the background physical observations of a field program carried out in August 1999 to document the fate of upwelled waters flowing offshore in the recurrent filament system rooted near Cabo Juby $\left(28^{\circ} \mathrm{N}\right)$. Sampling of a wide range of biogeochemical and biological processes reported elsewhere in this volume was carried out in both fixed and Lagrangian frameworks. Physical measurements 
provided the context to combine the disparate sampling demands within a coherent multi- and inter-disciplinary framework.

Up to a dozen eddies were identifiable near and immediately south of the islands in remote sensing and in a long section run across and south of the archipelago. Roughly half were cyclonic, of diameter up to about $50 \mathrm{~km}$, while the anticyclonic remainder approached twice that size as they moved downstream. Evolution of the filament structure as water progressed offshore was observed in transects spaced along the filament paths, and Argos drifters were released over the slope to trace longer-term surface layer motions in the filament system.

Greater complexity of circulation within and around the filament system was revealed than previously. Offshore transport of upwelled water in the filaments was seen for the first time to have multiple possible export or return paths. Location of origin and interaction with eddies determined water parcel retention within the upwelling system or dispersion to the open ocean. Direct estimates of offshore fluxes in the two filaments studied were broadly comparable to earlier determinations in the area.

\section{Methods}

From 2 to 27 August 1999, the Canaries filament system was studied during cruise He56 of R/V Hesperides. Vertical profiles of temperature, salinity and chlorophyll fluorescence were obtained with a Neil Brown Mk III Conductivitytemperature-depth (CTD) probe and Sea-Tech fluorometer mounted on a General Oceanics 24 bottle rosette sampler. CTD sensors were checked using digital reversing thermometers and water samples drawn for salinity determinations with an Autosal salinometer.

Currents were measured down to $\sim 300 \mathrm{~m}$ with a vessel-mounted $150 \mathrm{KHz}$ RDI acoustic Doppler current profiler (ADCP). The data were post-processed using the University of Hawaii CODAS software (Firing, Ranada \& Caldwell, 1995) to control quality, derive statistical information on the data set, and merge it with the available GPS position information to obtain absolute velocities. The amplitude and phase errors of the ADCP were determined and corrected by the method of Pollard \& Read (1989). Flooding rendered the instrument inoperable on 10 August. 
Four Serpé Argos drifters drogued at $15 \mathrm{~m}$ depth with WOCE design 'holey socks' were released during the cruise. A shock cord joined the small spherical surface float containing electronics and satellite transmitter to a sub-surface intermediary float and the drogue. Data were error-checked and then interpolated to 6 $\mathrm{h}$ intervals with a cubic spline.

Continuous underway measurements of surface $(\sim 2 \mathrm{~m})$ temperature and salinity were logged every minute using a Seabird thermosalinometer fed from the ship's continuous seawater supply. The calibration was checked by comparison with nearsurface values from the calibrated CTD record. Wind speed and direction, air temperature and atmospheric pressure were recorded at $1 \mathrm{~min}$ intervals approximately $10 \mathrm{~m}$ above sea level with an Anderaa meteorological station.

\section{Results}

\subsection{Winds}

The NW African upwelling system is driven by the Trade winds, which typically peak in July-August. The cruise took place under relatively weak trade winds (Fig. 1b). Maximum ship-measured winds in August 1999 were $<15 \mathrm{~m} \mathrm{~s}^{-1}$ as compared with $>20 \mathrm{~m} \mathrm{~s}^{-1}$ during August 1993 (Barton et al, 1998) and with $>15 \mathrm{~m} \mathrm{~s}^{-1}$ during JulyAugust 1995 (Barton et al., 2000) and June 1998 (Basterretxea, Barton, Tett, Sangrá, Navarro-Pérez \& Arístegui, 2002). The wind record reflects some topographically induced changes where the ship passed downwind of islands on 2-8, 13 and 22-24 August (Fig. 1c). Winds weakened gradually through the cruise until 22 August. The strongest winds of the cruise occurred at the end from 24 to 26 August.

\subsection{Surface structure}

AVHRR images revealed the spectacular scenario of a series of eddies spinning cyclonically (C) and anticyclonically (A) downstream of the islands of the Canaries archipelago (Fig. 2). The impression is of an eddy street progressing southwestward, though only a few eddies (A1 and C2) clearly moved downstream from the archipelago. In the series of images acquired during the study, despite occasional cloud, the development of individual eddies may be followed. C2 drifted southwestward at 5-6 $\mathrm{km} \mathrm{d}^{-1}$ from the southwestern flank of Gran Canaria to $27^{\circ} \mathrm{N}$ between 4 and 9 August. $\mathrm{C} 1$ developed in the original position of $\mathrm{C} 2$, but remained 
trapped to the island from 9 to on 27 August. Other trapped cyclones appeared intermittently west of La Palma (C3) and Hierro (C4), and an intense cyclone east of Hierro (C5) originated southwest of the small island of Gomera before 4 August, moved to $27.5^{\circ} \mathrm{N}$ within three days, and remained there throughout the rest of the month.

Anticyclone A1 was first seen on 7 August south of Tenerife, and drifted slowly south through 26 August. The anticyclones south of $27^{\circ} \mathrm{N}$ (A2 to A5) were observed in only a few images and could not be tracked. The one south of Gran Canaria (A6) developed rapidly around 23 August but did not separate appreciably from the island during the study. The intermittent anticyclone (A7) south of Fuerteventura also remained trapped behind its island.

Each island had a warm lee region caused by diurnal warming in the wind shadow of the islands (Barton et al., 2000). In some cases, the warmer lee waters were distorted by entrainment around the eddies.

Two filaments (F1 and F2) arising from the coast near Capes Bojador and Juby extended offshore to merge southwest of Fuerteventura, where they turned southward around the quasi-permanent cyclonic circulation (C7) trapped in the trough south of the inner islands. Despite its cyclonic nature, $\mathrm{C} 7$ appears warm in the centre because of the surrounding cooler filament waters. The filaments appeared discontinuous in the image of Fig. 2 where warm water in the lee of Fuerteventura extended southward across them, but on other occasions were unbroken. At their offshore limit, they were partly entrained around the anticyclone shed from the island of Gran Canaria (A6). Other filaments, F3 and F4, to the north and south of the study area, respectively, appeared throughout the cruise

\subsection{Long line}

The SST image for 7 August (Fig. 3a) reveals a single filament F1 extending from the continental shelf south of Cabo Juby in a cyclonic loop northwestwards towards Gran Canaria then southward and shoreward around C7. This configuration results from entrainment of the filament about the quasi-permanent cyclonic eddy $\mathrm{C} 7$ located over the trough south of the Canaries ridge (Barton et al., 1998). The line, sampled between 6 and 10 August, ran southeastward between the outer islands and then 
eastward into the African coast at Cabo Juby. It crossed the two cyclonic eddies C5 and $\mathrm{C} 2$, then cut the filament $\mathrm{F} 1$, crossed the north of the filament loop around $\mathrm{C} 7$, and intersected the filament again near its coastal origin. F2 was not evident at this time.

Uplifted iso-surfaces (Fig 4) mark the strong cyclone C5, the weaker C2, and a weak, third cyclonic eddy C3, west of La Palma, not evident in the SST image of 7 August. Between $\mathrm{C} 5$ and $\mathrm{C} 2$, isolines deepened well below the mean for the section, in the anticyclonic eddy A1. Weak doming of the isopycnals shoreward of $16^{\circ} \mathrm{W}$ was associated with the cyclonic circulation of the F1-C7 filament-eddy system. Note the slight surface warming in the centre of C7. The filament F1 appeared as a weak temperature minimum and body of lower salinity water in the upper $50 \mathrm{~m}$ in the section at $15.5^{\circ} \mathrm{W}$. This water was as low in salinity $(<36.3 \mathrm{psu})$ as the water upwelled at the coast. Indeed, the whole of the upper layer inshore of the filament circulation

had relatively low salinities ( $<36.5 \underline{\mathrm{psu}}$ ) of coastal, upwelled origin. Similarly, chlorophyll values in the Deep Chlorophyll Maximum (DCM) were higher within the filament circulation than outside it. An exception was that in cyclone $\mathrm{C} 5$ relatively high chlorophyll fluorescence extended from $50 \mathrm{~m}$ up to the sea surface. In the anticyclone A1 the DCM had deepened by more than $50 \mathrm{~m}$. The very high surface chlorophyll of the coastal upwelling did not extend beyond the shelf break.

The flow associated with the different features in the simultaneous ADCP sections (Fig. 5) was largely barotropic. Alternating bands of northward and southward flow defined the various eddies. The strong cyclone $\mathrm{C} 5$ had azimuthal flows in excess of $40 \mathrm{~cm} / \mathrm{s}$. Circulation in the outer part of the filament loop was southwestward, near the centre was weakly northeastward, and over the slope and shelf was more strongly northeastward in the recirculation of $\mathrm{C} 7$. The dynamic height relief of $\sim 20$ dynamic $\mathrm{cm}$ of the sea surface (and geostrophic currents) relative to $500 \mathrm{dbar}$ (and geostrophic velocities) coincided well with the measured velocity field. Shortly after completing this section, the ADCP failed.

\subsection{Filament cross-sections}

The structure of the filament system was sampled between 12 and 25 August. Sections labeled chronologically on the SST image of 17 August (Fig. 3b) are discussed in order of distance from shore. The SST image shows a second filament 
F2, oriented southwest towards F1, had developed in the Fuerteventura channel. The two filaments then flowed in parallel $\sim 30 \mathrm{~km}$ apart until they merged on turning southwest at $15^{\circ} \mathrm{W}$ near Gran Canaria.

Section 4 (18-19 August), across the Cabo Juby-Fuerteventura channel (Fig. 6), indicated upwelling of water of salinity $<36.4$ psu from below $125 \mathrm{~m}$ offshore into the surface layer near the African shore. The $17^{\circ} \mathrm{C}$ isotherm and 26.6 isopycnal, at 100$125 \mathrm{~m}$ offshore, rose only to around $25 \mathrm{~m}$ on the shelf because of surface warming. Inshore of the temperature front, chlorophyll fluorescence displayed a strong surface maximum. The maximum weakened rapidly seaward, and deepened to $\sim 50 \mathrm{~m}$ beneath the upwelled pycnocline. In mid-channel, filament F2 was indicated at the surface by relatively low temperature $\left(<22^{\circ} \mathrm{C}\right)$, high density anomaly $\left(>25.3 \mathrm{~kg} \mathrm{~m}^{-3}\right)$ and a local salinity minimum ( $<36.3 \mathrm{psu})$. At deeper levels, the thermocline and pycnocline were slightly elevated below the filament, the DCM showed locally high values at $25 \mathrm{~m}$ depth beneath the filament, and a sub-surface salinity maximum $(>36.5$ psu) at around $75 \mathrm{~m}$ depth was confined mainly to the north of the filament. Closer to Fuerteventura $\left(14.3^{\circ} \mathrm{W}\right)$ iso-surfaces dipped beneath the anticyclonic eddy A7 noted in Fig. 2.

F2 continued across Section 2 (13-14 August) where it was identifiable by temperature, density and chlorophyll fluorescence contours above $35 \mathrm{~m}$ depth breaking the surface around $27.75^{\circ} \mathrm{N}$ (Fig. 7). The filament was characterized by low surface-layer salinity $<36.3$ psu that extended down the pycnocline south of F2. Waters at the base of the pycnocline exhibited a salinity maximum ( $>36.5 \mathrm{psu})$ north of F2 and lower salinities to the south. Chlorophyll fluorescence values were highest at the surface in the filament, and elsewhere formed a maximum at the base of the pycnocline (26.3-26.5 kg m-3). F2 surface chlorophyll fluorescence was higher, and temperature lower, in Section 2 than in the closer-to-shore Section 4. Winds had weakened significantly in the 5 days between sections. Section 2 also showed a pronounced doming of iso-surfaces below $\sim 50 \mathrm{~m}$, centered around $27.55^{\circ} \mathrm{N}$. This is related to a small cyclone discussed later.

The next line offshore, Section 1 (12-13 August) and its repetition as Section 5 (19-20 August), crossed both filaments F1 and F2, seen as two bands of uplifted isotherms and isopycnals intersecting the surface near $27.4^{\circ} \mathrm{N}$ and $27.6^{\circ} \mathrm{N}$ (Figs. 8 and 9). Scant 
or no chlorophyll fluorescence signal was evident near surface in either filament. The DCM, at the base of the pycnocline, showed slightly increased chlorophyll fluorescence below the filaments. As before, F2 transported lower salinity surface water $(<36.4 \mathrm{psu})$, which extended down the pycnocline toward the south. The subsurface structure showed an overall deepening of the isopycnals to the north, indicative of general offshore geostrophic flow. F2 was weaker than in Section 2, although this line was only some $20 \mathrm{~km}$ farther offshore.

Section 6 (21 August) ran northward from the intersection of filament F1 with Sections 1 and 5. Only F1 was evident, at the southern end of the line (Fig. 10), where shallow isopycnals and isotherms broke surface in an area of slightly reduced salinity. The DCM was undisturbed across this section. Either F2 had moved to and beyond the northern limit of the line or its hydrographic signal had become undetectable.

In Section 7 (23-24 August), situated $50 \mathrm{~km}$ farther offshore, neither filament was strongly evident (Fig. 11), although the SST images suggest both were detectable at this distance offshore. A weak decrease of temperature near $27.65^{\circ} \mathrm{N}$ possibly reflected a surface expression of F1, while a similar weak indication of F2 occurred near $27.9^{\circ} \mathrm{N}$. The pycnocline and deeper isopycnals domed around $27.7^{\circ} \mathrm{N}$, indicative of a band of strong offshore flow. This coincided with a weak maximum in the DCM at the base of the pycnocline near $28^{\circ} \mathrm{N}$, possibly representing the main flow of $\mathrm{F} 2$. The decreasing wind during Sections 5, 6 and 7, and their distance offshore, may have had some effect in weakening the surface filament signal.

Section 8 (25 August) crossed the southward turning filaments into the anticyclonic eddy A6, which had developed in the previous days (Fig. 12). The surface filament waters were seen by a slight decrease of surface temperature and salinity towards $27.5^{\circ} \mathrm{N}$. All iso-surfaces sloped strongly down into the eddy, which was separated from filament waters by a sharp salinity gradient at $100 \mathrm{~m}$ depth. Chlorophyll fluorescence values in the DCM were significantly higher on the filament side of the boundary. Surface temperature increased towards the eddy centre. 


\subsection{Velocity field}

A dynamic height map (Fig. 13a) relative to 500 dbar including all stations inshore of Gran Canaria, irrespective of timing, reveals velocity structures associated with the filaments and eddies described above. The field was smoothed objectively to suppress features smaller than 0.25 degrees because of the lack of synopticity and the irregular station spacing. The anticyclones A6 and A7 were evident south of Gran Canaria and Fuerteventura, respectively, while the northern limit of cyclone $\mathrm{C} 7$ entered the south of the map. Possible paths of filaments F2 (0.660-0.665 dyn m) and F1 (0.645-0.650 dyn m) may be traced along the contours of dynamic height, in agreement with their identification in the SST images. F2 entered the area across the Fuerteventura Section 4, then crossed the northern part of Section 2 and associated station grid. It continued obliquely across the filament Section 1 to meet F1 entering from the south. Both filaments appeared to cross Section 6 and its associated station grid (although only F1 could be identified in that section's hydrography). Both continued northwest across and south of Section 7 to turn south near Gran Canaria where they met the strong flow on the eastern limb of anticyclone A6.

Inshore of and between filaments F1 and F2, two new features were identifiable: the dipole eddy pair $\mathrm{C} 8$ and $\mathrm{A} 8$ that occupied the southern part of Section 2. Between them, a strong shoreward flow was indicated. This interpretation agrees with the disposition of SST seen in Fig. 3b, where the complicated structure sampled by the inshore lines can be resolved as the eddy pair A8-C8, bounded to their north and south by cold filaments F2 and F1, respectively, and separated by a cool return flow between.

The two small filament surveys (Fig. 13b and c), contoured at the higher resolution allowed by the close station spacing and the small area covered, revealed smaller scale structure. Temporal variability of dynamic height was assessed from a reoccupation of one line of the near-shore grid after two days and from two time series stations (Fig. 13d). Comparison of the repeated dynamic height profiles of the line with the variability $(+/-0.008$ dyn $m)$ over $24 \mathrm{~h}$ at the drift station just south of the near-shore grid suggested that spatial structure shorter than $10 \mathrm{~km}$ was indistinguishable from diurnal variations. Greater variation (+/-0.022 dyn $\mathrm{m})$ at a drift station farther offshore occurred in a region of stronger horizontal gradients. The 
smoothing chosen for the grid maps therefore suppressed scales shorter than $10 \mathrm{~km}$. In the resultant near-shore grid map (Fig. 13c), filament F2 was seen in the centre, while weak recirculation related to C8 was indicated to its south. Similarly the offshore grid map (Fig. 13b) showed F2 crossing to the northwest while F1 meandered across the southwestern portion of the grid. Cyclonic and anticyclonic circulations occurred north of the main flow.

Individual geostrophic velocity sections were smoothed horizontally with a Hanning filter to eliminate shorter scale features, as for the maps. However, the sections retained more detail (noise), as the maps were smoothed in two dimensions rather than one. The offshore flow in F2, across the Fuerteventura Section 4 (Fig. 14a), reached $0.3 \mathrm{~m} \mathrm{~s}^{-1}$ and the velocity signal extended deeper than $200 \mathrm{~m}$. Closer to Fuerteventura reverse flow associated with anticyclone A7 was weaker. Similar offshore flow in F2 continued across the north of Section 2 (Fig. 14b), but shoreward flow above $100 \mathrm{~m}$ in the south related to the return flow between $\mathrm{C} 8$ and A8. Section 1 showed only weak flow normal to the section (Fig. 14c) because both filaments F1 and F2 crossed it obliquely.

In Section 6, the most offshore of the small grid (Fig. 14d), the offshore flow at the southern limit of the section lay south of the surface expression of F1 in the hydrography, which coincided with a weak shoreward flow. However, the map of Fig. $13 \mathrm{~b}$ indicates this was a recirculation, which probably related to smaller scale eddying

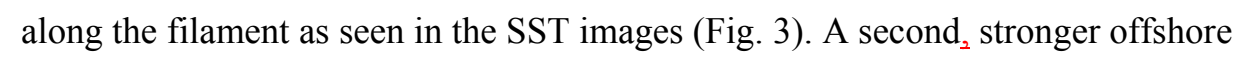
flow near $27.71^{\circ} \mathrm{N}$ most likely represents F2, even though little surface signal of F2 was evident in the hydrography section. Similarly in Section 7 (Fig. 14e), one band of offshore flow corresponded to a weak surface expression of F1, but the strongest offshore flow around $27.8^{\circ} \mathrm{N}$ was considerably south of the weak surface temperature minimum ${ }_{2}$ possibly indicating F2. Both bands of offshore flow did correspond to local maxima in the DCM.

Maps of the temperature, salinity and density at $10 \mathrm{~m}$ and chlorophyll fluorescence at $25 \mathrm{~m}$ depth for the same small grid indicated partial correspondence between the hydrographic properties and the flow field (Fig. 15). Lower temperature and salinity, plus higher chlorophyll fluorescence, suggested a more direct path of F1 across the southwest of the grid than the meandering suggested by the dynamic topography. The 
only hydrographic indication of F2 was the slightly lower temperature and salinity in the northeast, but this was north of the path indicated by the dynamic height. The identification of a particular band of dynamic height with the surface hydrographic signal of the filaments may be somewhat arbitrary, and the actual relationship may have changed along the filament. However, the positions of the filaments in the dynamic topography do correspond with those seen in the satellite image of Fig. $3 \mathrm{~b}$ of 17 August, some 5 days earlier. Although the surface expressions of F1 and F2 may be displaced northward, the dynamic height map and geostrophic sections probably indicate the main flow of the filaments. The small-scale re-circulations observed and the weaker wind conditions could well weaken the filament surface signal in the offshore sections 6 and 7 .

In Section 8, south of Gran Canaria (Fig. 14f), strong southward flow occurred in two bands. One north of $27.6^{\circ} \mathrm{N}$ marked the edge of the adjacent merged filament circulation identifiable by its higher chlorophyll fluorescence in Fig. 12, while the other represented the eastern limb of the anticyclone A6 flowing with speeds up to 0.6 $\mathrm{m} \mathrm{s}^{-1}$ at the surface. A narrow band of weak reversed flow between them probably represented instabilities on the edge of the anticyclone, represented in the hydrography by the sharp salinity gradient.

\subsection{Drifter trajectories}

On 14 August four Argos drifters were released where F1 had been detected in the initial long section and satellite images. One failed after launch, but the other three moved shoreward to circulate cyclonically until the end of the cruise around an area of warmer water south of F2 (Fig. 16a). This is the eddy C8, identifiable as a low in the dynamic height map (Fig. 12) and as domed isopycnals in Section 2 (Fig. 7).

Two of the drifters, 4574 and 4771, performed one small rotation close together in the centre of the warm patch while 4949 circulated farther out around the edge of the elliptical structure. After the first circuit, 4771 continued to make smaller loops within the eddy, but 4574 tracked 4949 closely around its periphery. The rotation period of the two inner drifters was $\sim 6 \mathrm{~d}$ while that for 4949 was $\sim 12 \mathrm{~d}$. Scalar speeds were $\sim 0.15 \mathrm{~m} \mathrm{~s}^{-1}$ but almost doubled for 4949 and 4574 when the drifters moved briefly along the boundary of filament F2. No drifter was captured in filaments F1 or F2 to be transported offshore; all were subsequently caught up in alongshore flow. 
The subsequent path of one drifter (Fig. 16b) showed significant onshore-offshore exchange over the following months. After several circuits of C8, buoy 4771 moved equatorward for 14 days, from water $2000 \mathrm{~m}$ deep to within the $100 \mathrm{~m}$ isobath on the shelf. It then followed an offshore and northward trajectory while describing cyclonic loops of $\sim 50 \mathrm{~km}$ diameter with a period again $\sim 6 \mathrm{~d}$. Whether this was the same eddy, $\mathrm{C} 8$, is doubtful, but it most probably was an island-generated eddy. The westward motion is qualitatively consistent with $\beta$-effect (Nof, 1981). The motion persisted until December, when the drifter circuited the island of El Hierro and left the area. The trajectory illustrates the often convoluted paths of water parcels, which may move on and off the shelf, the longevity of the eddies, and an apparent flow reversal during the autumn months.

\subsection{TS properties of the filaments}

The underlying water mass is a variant of the North Atlantic Central Water (Sverdrup, Johnson \& Fleming, 1942), the Eastern North Atlantic Water (ENAW) defined by Fiuza \& Halpern (1978), which has its warm salty limit near $21.5^{\circ} \mathrm{C}, 37.3$ psu. The upper layer waters in the filament area occupy a range of more than 0.3 in salinity and $6^{\circ} \mathrm{C}$ in temperature, from low salinity, low temperature upwelled waters to salty, warm oceanic waters (Fig. 17). Below 36.5 psu and below $18^{\circ} \mathrm{C}$, the TS curves show a slope opposite to that of the ENAW, but in the rest of the range, the distribution indicates evidence of warmed ENAW surface waters. Filament F1 waters consisted of sub-surface water from the low salinity end of the range below a higher salinity surface layer, while conversely F2 had higher salinity sub-surface waters capped by a lower salinity surface layer.

These features have a straightforward explanation. In summer, the surface water is exposed to heating. Oceanic surface water at the upper end of the ENAW range warms cumulatively during summer to an equilibrium represented by the vertical extension towards higher temperatures seen at the right hand side of Fig.17. Water upwelled at the coast undergoes transitions that are more complex:-

1. Near shore, lower salinity and temperature upwells into the surface layers.

2. Upwelled water is rapidly warmed to form a TS curve parallel to the temperature axis. 
3. At the same time, the warmed, low salinity upwelled water moves offshore in the surface Ekman layer. It mixes with the underlying cooler, saltier water because of wind action and vertical current shear. This results in the reversed slope of the upwelled shelf TS curves seen as branches separating from the ENAW curve at density anomalies greater than $26.6 \mathrm{~kg} \mathrm{~m}^{-3}$ (depth $\sim 100 \mathrm{~m}$ ). ENAW

4. As the modified upwelled water advances farther offshore, stronger stratification reduces the vertical mixing, while continued surface heating extends the TS curve to higher temperatures.

$\mathrm{So}_{2}$ near-shore upwelled water, exemplified in Fig. 17 by station 131 off Cabo Juby, showed limited heating and mixing with sub-surface water waters. Peak summer heat input in the area is around $200 \mathrm{~W} \mathrm{~m}^{-2}$. Given the observed mixed layer depth of around $10 \mathrm{~m}$, this implies that newly upwelled water warms at about $0.4^{\circ} \mathrm{C}$ per day, so that Station 131 surface waters are probably about 5 days old. Stations farther from shore had higher salinity, indicative of upwelling from shallower depths, and progressive amounts of warming. Horizontal exchanges and advection produce profiles with an intermediate range of properties. Within the filament sections, the saltiest, most oceanic water occurred to the north of F2, as at station 141. Most other water in the sections, even offshore, seemed to have been upwelled, mixed and warmed earlier. This was consistent with the retention of most waters south of F2 within the general recirculation associated with the cyclonic eddy $\mathrm{C} 7$ and filament F1. The northern filament F2 (e.g. stations 52 and 66) was composed of low salinity ( $\sim 36.35 \mathrm{psu}$ ) water that had been upwelled from about $100 \mathrm{~m}$, warmed and advected over oceanic waters. F1 surface waters (e.g. station 57$)$ were salty ( $\sim 36.5 \mathrm{psu})$, indicative of upwelling from depths $<100 \mathrm{~m}$ at their source south of Cape Juby. They had been warmed considerably as they were advected over lower salinity, older upwelled waters. Indeed F1 was warmer than F2, but this was only because it was sampled in the sections farther from its source. The situation was consistent with F1 being the main structure while the more intermittent F2 was overlaid on oceanic waters.

\section{Discussion}


The recurrence of filaments in the region of Cabo Juby every year is related to the quasi-permanent eddy (C7) located over the bathymetric trough downstream of the shallower Fuerteventura-Africa channel. Potential vorticity conservation ${ }_{2}$ as the alongshore flow encounters deeper water of the trough ${ }_{2}$ produces the eddy as long as the flow through the zone is equatorward (during most of the year). A filament would form whenever coastal upwelling is strong enough for the upwelling front and

Eliminado: was

Eliminado: was associated current jet to expand beyond the shelf to be entrained around the eddy. This view is based on observations made in summers of 1993 (Barton et al., 1998), 1995 (Barton et al., 2000), 1998 (unpublished data) and the present study of 1999. Hagen, Zulicke \& Feistel (1996) made a similar argument for topographic control of the Cabo Ghir filament at $31^{\circ} \mathrm{N}$.

The most detailed study of the filament until now was that of 1993, when a single filament extended northwest from between Cabo Juby and Cabo Bojador to wrap around the eddy. However, the three later studies all showed a dual filament structure. The origin of the northern filament seems related to the development of the anticyclonic eddy A7 in the lee of Fuerteventura. Given flow separation and anticyclone generation southeast of the island, entrainment of upwelled water from the African shelf would occur, as for C7. The two eddies A7 and C7 are far enough apart to produce individual filaments separated by the re-circulations of $\mathrm{C} 8$ and $\mathrm{A} 8$. Farther offshore, the two filaments merge into a single weak feature.

The two filaments had quite distinct TS properties indicative of different origins. Both were relatively shallow features overlying contrasting deeper waters. The northern F2 overlay more oceanic, saltier waters, while F1 overlay waters of TS signature suggestive of older upwelled water. This suggests that F1 is the more permanent feature, and that it and the related cyclone $\mathrm{C} 7$ form a system that extends the influence of the coastal upwelling offshore some $200 \mathrm{~km}$. The strong salinity boundary seen at $16^{\circ} \mathrm{W}$ in Fig. $4 \mathrm{~d}$ marks the offshore limit of this system. The more oceanic water properties below F2 suggest greater intermittency in its occurrence, related perhaps to the appearance and disappearance of A7, However, since both are transporting shelf upwelled waters, they may have an important influence on enrichment of offshore waters. 
Results for offshore volume transport in the filaments above $300 \mathrm{~m}$ are summarized in Table 1. Estimates were not possible for Section 5 (repeat of Section 1) because several of the CTD casts suffered data loss in the upper layers. In Section 7 it was impossible to identify with any certainty the velocity structures associated with the filaments. On Sections 1 and possibly 6 the sampling was not at right angles to the filament so that geostrophic fluxes may underestimate the true flow. Estimated transport for $\mathrm{F} 2$ was around $10^{6} \mathrm{~m}^{3} \mathrm{~s}^{-1}$ for the better defined estimates. The lowest value of $0.3 \times 10^{6} \mathrm{~m}^{3} \mathrm{~s}^{-1}$ of Section 1 seems an underestimate related to the oblique crossing of the filament. The smaller F1 transports also seem to be underestimates, caused as above and by incomplete coverage of the filament width. The transport in the most offshore section (8) was estimated for the merged filaments as $1.5 \times 10^{6} \mathrm{~m}^{3} \mathrm{~s}$ ${ }^{1}$, roughly the sum of the estimates for the individual filaments. The ADCP transport where $\mathrm{F} 1$ crossed the initial long line is the most reliable estimate ${ }_{2}$ because the directly measured velocity component along the observed direction $\left(193^{\circ}\right)$ of the filament was available. This direct estimate was relative to $200 \mathrm{~m}$ depth $\mathrm{b}_{2}$ because of the shallow ADCP penetration ${ }_{2}$ but was close to the corresponding geostrophic estimate above $300 \mathrm{~m}$. The transport relative to $200 \mathrm{~m}$ for Section 8 was not much less, $1.3 \times 10^{6} \mathrm{~m}^{3} \mathrm{~s}^{-1}$.

These estimates are similar to those for the single Juby filament observed in 1993 (Navarro Perez \& Barton, 2000) and to the lower estimates in California Current filaments (Flament, Armi \& Washburn, 1985; Ramp, Jessen, Brink, Niiler, Daggett \& Best, 1991). Filaments occur at roughly $200 \mathrm{~km}$ intervals along the coast, so between Cabo Blanco $\left(20^{\circ} \mathrm{N}\right)$ and Casablanca $\left(33^{\circ} \mathrm{N}\right)$, a total off-shelf flow of $6-9 \times 10^{6} \mathrm{~m}^{3} \mathrm{~s}^{-1}$ might be expected. Although most of this flow re-circulates shoreward, as around the Cabo Juby eddy C7, biological processes, sinking at filament boundaries, horizontal entrainment and mixing with offshore waters will ensure a net export of material from the shelf. To put this in context, the mean flow of the Canary Current above $200 \mathrm{~m}$ between $35^{\circ} \mathrm{W}$ and the coast is estimated at around $4 \times 10^{6} \mathrm{~m}^{3} \mathrm{~s}^{-1}$ (Stramma \& Siedler, 1988), while the flow of North Atlantic Central Water between Lanzarote and the coast was $0.8 \pm 1.1 \times 10^{6} \mathrm{~m}^{3} \mathrm{~s}^{-1}$ from a four-year current meter array (Hernández-Guerra, Fraile-Nuez, Borges, López-Laatzen,Vélez-Belchi, Parrilla et al., 2003). Thus, the exchanges related to filaments represent a major recycling of upper layer waters across the continental slope. 
The observed northward motion of the drifter reporting from October to December adds to a growing body of evidence of a major flow reversal within several hundred kilometers of the coast in autumn. Stramma \& Siedler (1988) reported a geostrophic surface flow poleward over the slope in autumn, albeit not statistically significant, in their analysis of the historical hydrographic data base, and Navarro-Perez \& Barton (2001) found periods of northward flow late in the year indicated by sea level differences across the archipelago. Hernández-Guerra et al. (2003) and Knoll, Hernandez-Guerra, Lenz, Laatzen, Machin, Muller et al. (2002) observed northward transport above $\sim 600 \mathrm{~m}$ every October-November from 1997 to 2000 at current moorings in the Lanzarote channel. Hernández-Guerra, Machin, Antoranz, CisnerosAguirre, Gordo, Marrero-Díaz et al. (2002) reported similar results based on monthly XBT sections across the same passage. These observations have been interpreted as surfacing of the poleward slope undercurrent when upwelling weakens, but the typical $100 \mathrm{~km}$ width of the undercurrent (Barton, 1989) is much less than that of the flow indicated by the present drifter.

Marchesiello, McWilliams \& Shchepetkin (2003) emphasized the importance of mean-seasonal atmospheric forcing, coupled with topography and stratification, in determining the mesoscale variability. They successfully modeled California Current mean currents and associated topographically linked standing eddies using the ROMS model forced by mean atmospheric field forcing. Moreover, they showed that much of the mesoscale variability, expressed in terms of upwelling fronts, jets and filaments, was intrinsic and independent of transient forcing. They also found the $\beta$-effect produced alongshore pressure gradients giving rise to realistic current shears. Baroclinic instability in their $3.5 \mathrm{~km}$ resolution model produced most of the variability, while lateral shear instability contributed near shore.

The Cape Juby eddy-filament system could be an example of such mechanisms, dependant as it is on the interaction of topography with the background flow. Equally high resolution modeling of the Canary Current remains to be achieved. Johnson \& Stevens (2000) produced realistic larger scale circulation patterns with a $25 \mathrm{~km}$ resolution model driven by monthly mean atmospheric forcing, but did not resolve detail on the scale of the present study. Batteen, Martinez, Bryan \& Buch (2000) also investigated the northern Canary Current numerically, without $\beta$-effect or bottom 
topography. Again, the coarse resolution precluded any detailed comparison with structures like those of our study.

Clearly, further process studies are required to define the in situ characteristics of flow and exchanges, horizontal and vertical, of this complex and unique system. The persistent recurrence of the structures over many years makes them amenable to repeated study. To understand fully the range of interactions and exchanges between the eddy field and the upwelling filaments and their net effect in transport of material offshore, more detailed numerical modeling will be needed.

\section{Acknowledgements}

This work has been supported by the European Union (project CANIGO, MAS3.CT96-0060). We thank the officers and crew of the BIO Hespérides, as well as the staff of the UTM (CSIC, Spain) for their invaluable help at sea. Analysis and writing up was supported by Catedra Patrimonial EX-010009 (Conacyt) while EDB was on sabbatical leave at CICESE, Mexico.

\section{References}

Arístegui, J., Sangrá, P., Hernández-Leon, S., Cantón, M., Hernández-Guerra, A. \& Kerling, J.L. (1994) Island-induced eddies in the Canary Islands. Deep-Sea Res., 41(10), 1509-1525.

Arístegui, J., Tett, P., Hernández-Guerra, A., Basterretxea, G., Montero, M.F., Wild, K., Sangrà, P., Hernández-León, S., Cantón, M., García-Braun, J.A., Pacheco, M. $\&$ Barton, E.D. (1997). The influence of island-generated eddies on chlorophyll distribution: a study of mesoscale variation around Gran Canaria. Deep-Sea Research I, 44, 71-96.

Barton, E.D. (1989) The poleward undercurrent on the eastern boundary of the Subtropical North Atlantic. In APoleward flows along Eastern Ocean Boundaries@ (Ed S.Neshyba, R.L., Smith, C.N.K.Mooers) pp 82-95. Springer-Verlag Lecture Note Series.

Barton, E.D., Arístegui, J., Tett, P.,.Cantón, M., García-Braun, J., Hernández-León, S., Nykjaer, L., Almeida, C., Almunia, J., Ballesteros, S., Basterretxea, G., Escánez, J., García-Weill, L., Hernández-Guerra, A., López-Laatzen, F., Molina, R., Montero, M.F., Navarro-Pérez, E., Rodríguez, J.M., van Lenning, K., Vélez, 
H. \& Wild, K. (1998). The transition zone of the Canary Current upwelling region. Progress in Oceanography, 41, 455-504

Barton, E.D., Basterretxea, G., Flament, P., Mitchelson-Jacob, E.G., Jones, B., Arístegui, J. \& Herrera, F. (2000) The lee of Gran Canaria. Journal of Geophysical Research, 105, 17,173-17,193.

Basterretxea, G. \& Arístegui, J. (2000). Mesoscale variability in phytoplankton biomass distribution and photosynthetic parameters in the Canary-NW African coastal transition zone. Marine Ecology Progress Series, 197, 27-40

Basterretxea, G., Barton, E.D., Tett, P., Sangrá, P., Navarro-Pérez, E. \& Arístegui, J. (2002). Eddy and DCM response to wind shear in the lee of Gran Canaria. DeepSea Research I, 49, 1087-1101.

Batteen, M.L., Martinez, J.R., Bryan, D.W. \& Buch, E.J. (2000) A modeling study of the coastal eastern boundary current system off Iberia and Morocco. Journal of Geophysical Research, 105, 14173-14195

Brink, K. \& Cowles, T. (1991). The coastal transition zone experiment. Journal of Geophysical Research, 96, 14637-14647.

Firing, E., Ranada, J. \& Caldwell, P. (1995) Processing ADCP data with the CODAS software system. Joint Institute for Marine and Atmospheric Research, School of Ocean and Earth Science and technology, University of Hawaii, 139 pp.

Fiuza, A.F.G. \& Halpern, D. (1978) Hydrographic observations of the Canary Current between $21^{\circ} \mathrm{N}$ and $25.5^{\circ} \mathrm{N}$ during March-April 1974. Rapp. P.-v. Reun. Cons. Int. Explor. Mer, 181.

Flament P., Armi, L. \& Washburn, L. (1985) The evolving structure of an upwelling filament. Journal of Geophysical Research, 90, 11765-11778.

Hagen, E., Zulicke, C. \& Feistel, R. (1996) Near-surface structures in the Cape Ghir filament off Morocco. Oceanologica Acta,19 (6): 577-598 1996.

Hernández-Guerra, A., Machin, F., Antoranz, A., Cisneros-Aguirre, J., Gordo, C., Marrero-Díaz, A., Martínez, A., Ratsimandresy, A.W., Rodríguez-Santana, A., Sangrá, P., López-Laazen, F., Parrilla, G., Pelegrí, J.L, Temporal variability of mass transport in the Canary Current. Deep-Sea Research Part II-Topical Studies in Oceanography, 49 (17): 3415-3426 2002.

Hernández-Guerra, A., Fraile-Nuez, E., Borges, R,.López-Laatzen,F.,Vélez-Belchi, P., Parrilla, G., Müller, T.J. (2003) Transport variability in the Lanzarote passage 
(eastern boundary current of the North Atlantic subtropical gyre). Deep-Sea Research Part I, 50, 189-200.

Johnson, J. \& Stevens, I. (2000) A fine resolution model of the eastern North Atlantic between the Azores, the Canary Islands and the Gibraltar Strait. Deep-Sea Research Part I, 47, 5, 875-900.

Joint, I., Inall, M., Torres, R., Figueiras, F.G., Álvarez-Salgado, X.A., Rees, A.P. \& Woodward, E.M.S. (2001). Two lagrangian experiments in the Iberian upwelling system: tracking an upwelling event and an off-shore filament. Progress in Oceanography, 51, 221-248.

Knoll, M., Hernandez-Guerra, A., Lenz, B., Laatzen, F.L., Machin, F., Muller, T.J. \& Siedler, G. (2002) The Eastern Boundary Current system between the Canary Islands and the African Coast. Deep-Sea Research Part II, 49 (17): 3427-3440 Marchesiello, P., McWilliams, J.C. \& Shchepetkin, A. (2003) Equilibrium structure and dynamics of the California Current system. Journal of Physical Oceanography, 33, 753-783.

Navarro-Pérez, E. \& Barton, E.D. (1998) The physical structure of an upwelling filament off the north-west African coast during August 1993. South African Journal of Marine Science, 19, 61-74.

Navarro-Pérez, E. \& Barton, E.D. (2001) Seasonal and interannual variability of the Canary Current. Scientia Marina, 65, 205-213.

Nof, D. (1981) On the beta-induced movement of isolated baroclinic eddies. Journal of Physical Oceanography, 11, 1662-1672.

Ramp S.R., Jessen, P.F., Brink, K.H., Niiler, P.P., Daggett, F.L. \& Best, J.S (1991) The physical structure of cold filaments near Point Arena, California, during June 1987. Journal of Geophysical Research, 96, 14859-14884.

Rodríguez, J.M., Hernández-Leon, S. \& Barton, E.D. (1999) Mesoscale distributions of fish larvae in relation to an upwelling filament off Northwest Africa. Deep-Sea Research, I, 46, 1969-1984.

Sverdrup, H.U., Johnson, M.W. \& Fleming, R.H. (1942) The Oceans, Prentice Hall, N.Y., 1087 pp.

Van Camp L., Nykjaer, L., Mittelstaedt, E. \& Schlittenhardt, P. (1991) Upwelling and boundary circulation off Northwest Africa as depicted by infrared and visible satellite observations. Progress in Oceanography, 26, 357-402. 


\section{Figure legends}

Fig. 1 (a) Northeast central Atlantic region showing schematic major eastern boundary currents. The summer trade winds blow southwestward over this area. Box shows location of the present study.

(b) Ship board wind vectors. North is aligned up the ordinate. The apparent wind reversals are in the lee of islands and do not reflect changes in the synoptic meteorology. Section numbers and labels indicate the timing of sampling referred to in the text.

(c) Elevation west-east across the Canaries archipelago shows the abrupt topography of the mountainous islands, which produces numerous eddies downstream.

Fig. 2 Sea surface AVHRR temperature image of 24 August 1999. Cyclonic (C) and anticyclonic (A) eddy and filament (F) locations discussed in the text are labeled.

Fig. 3 Sea surface temperature images of (a) 7 August 1999 and (b) 17 August 1999. Labeled dots indicate station positions. The 'long line' across the archipelago indicated in (a) and the numbered sections and features in (b) are discussed in the text.

Fig. 4 For the initial long line of Fig. 3a: (a) Surface temperature profile with features labeled, (b) surface salinity with features labeled, (c) vertical section of temperature, (d) vertical section of salinity, (e) vertical section of density anomaly and (f) vertical section of chlorophyll fluorescence. Cyclones (C), anticyclones (A) and filaments (F) are labeled in (a) and (b).

Fig. 5 For the initial long line of Fig. 3a: (a) Surface dynamic height anomaly with respect to a 500 dbar reference, (b) vertical section of ADCP eastward velocity component - eastward flow shaded, (c) vertical section of ADCP northward velocity component - northward flow shaded. Cyclones (C), anticyclones (A) and filaments (F) are labeled in (a).

Fig. 6 For Section 4 of Fig. 3b: (a) Surface temperature profile with features labeled, (b) surface salinity with features labeled, (c) vertical section of temperature, (d) vertical section of salinity, (e) vertical section of density anomaly and (f) vertical section of chlorophyll fluorescence. 
Fig. 7 For Section 2 of Fig. 3b: (a) Surface temperature profile with features labeled, (b) surface salinity with features labeled, (c) vertical section of temperature, (d) vertical section of salinity, (e) vertical section of density anomaly and (f) vertical section of chlorophyll fluorescence.

Fig. 8 For Section 1 of Fig. 3b: (a) Surface temperature profile with features labeled, (b) surface salinity with features labeled, (c) vertical section of temperature, (d) vertical section of salinity, (e) vertical section of density anomaly and (f) vertical section of chlorophyll fluorescence.

Fig. 9 For Section 5 of Fig. 3b: (a) Surface temperature profile with features labeled, (b) surface salinity with features labeled, (c) vertical section of temperature, (d) vertical section of salinity, (e) vertical section of density anomaly and (f) vertical section of chlorophyll fluorescence.

Fig. 10 For Section 6 of Fig. 3b: (a) Surface temperature profile with features labeled, (b) surface salinity with features labeled, (c) vertical section of temperature, (d) vertical section of salinity, (e) vertical section of density anomaly and (f) vertical section of chlorophyll fluorescence.

Fig. 11 For Section 7 of Fig. 3b: (a) Surface temperature profile with features labeled, (b) surface salinity with features labeled, (c) vertical section of temperature, (d) vertical section of salinity, (e) vertical section of density anomaly and (f) vertical section of chlorophyll fluorescence.

Fig. 12 For Section 8 of Fig. 3b: (a) Surface temperature profile with features labeled, (b) surface salinity with features labeled, (c) vertical section of temperature, (d) vertical section of salinity, (e) vertical section of density anomaly and (f) vertical section of chlorophyll fluorescence.

Fig. 13 Dynamic height (dynamic metres) map of 0/500 dbar for:

(a) all filament sections. Eddies discussed in the text are labeled. The shaded areas represent the paths of the two filaments F1 and F2.

(b) small scale offshore grid around Section 6. F1 and F2 are shaded.

(c) near-shore grid around Section 2. F2 is shaded. 
(d) Dynamic topography 0/500 dbar along line indicated in (c) repeated 2 days apart. Vertical line shows twice the standard deviation of dynamic height observed in nearby 24 hour time series.

Fig. 14 Sections of geostrophic velocity in $\mathrm{cm} \mathrm{s}^{-1}$ for (a) Section 4, (b) Section 2, (c) Section 1, (d) Section 6, (e) Section 7, (f) Section 8. The positions of the filament surface signal are indicated above each frame. In lines 6 and 7, the surface signal of F2 was displaced from the current jet. 'Offshore' flow is shaded. The abscissa for (a) is in degrees of longitude; others are latitude.

Fig. 15 Maps of (a) temperature and (b) salinity at $10 \mathrm{~m}$, (c) chlorophyll fluorescence at $25 \mathrm{~m}$ depth, and (d) surface dynamic height $0 / 500 \mathrm{dbar}$ in the grid of stations around Section 2. Shaded bands trace the paths of F1 and F2 as in Fig. 13.

Fig. 16 (a) Drifter trajectories superimposed on the SST image of 18 August 1999. Drifter positions are marked every two days at midnight. Eddies and filaments mentioned in the text are labeled. (b) Trajectory of drifter 4771 from August to December 1999. Year day is labeled every 4 days along the path. Isobath depths in $\mathrm{m}$ are labeled.

Fig. 17 TS plots for Sections 1 to 7. Selected labeled stations are plotted as continuous lines to illustrate points discussed in the text. Note the contrasting properties of filaments F1 and F2 (boxes). 
Table 1 Offshore geostrophic transport in Sverdrups $\left(=10^{6} \mathrm{~m}^{3} \mathrm{~s}^{-1}\right)$ above $300 \mathrm{~m}$.

\begin{tabular}{|l|l|l|l|l|}
\hline Section & Date & F1 & F2 & Comment \\
\hline 4 & $18-19$ Aug & - & 1.3 & Well defined \\
\hline 2 & $13-14$ Aug & - & 0.9 & Well defined \\
\hline 1 & $12-13$ Aug & 0.4 & 0.3 & Oblique section not covering entire F1 \\
\hline 6 & 21 Aug & 0.4 & 1.1 & F1 partially sampled \\
\hline 8 & 25 Aug & F1+F2 & $=1.5$ & Merged filament total \\
\hline $\begin{array}{l}\text { Long } \\
\text { line }\end{array}$ & $9-10$ Aug & 1.5 & - & $\begin{array}{l}\text { Only directly measured transport (above } \\
\text { 200m), before appearance of F2 }\end{array}$ \\
\hline
\end{tabular}




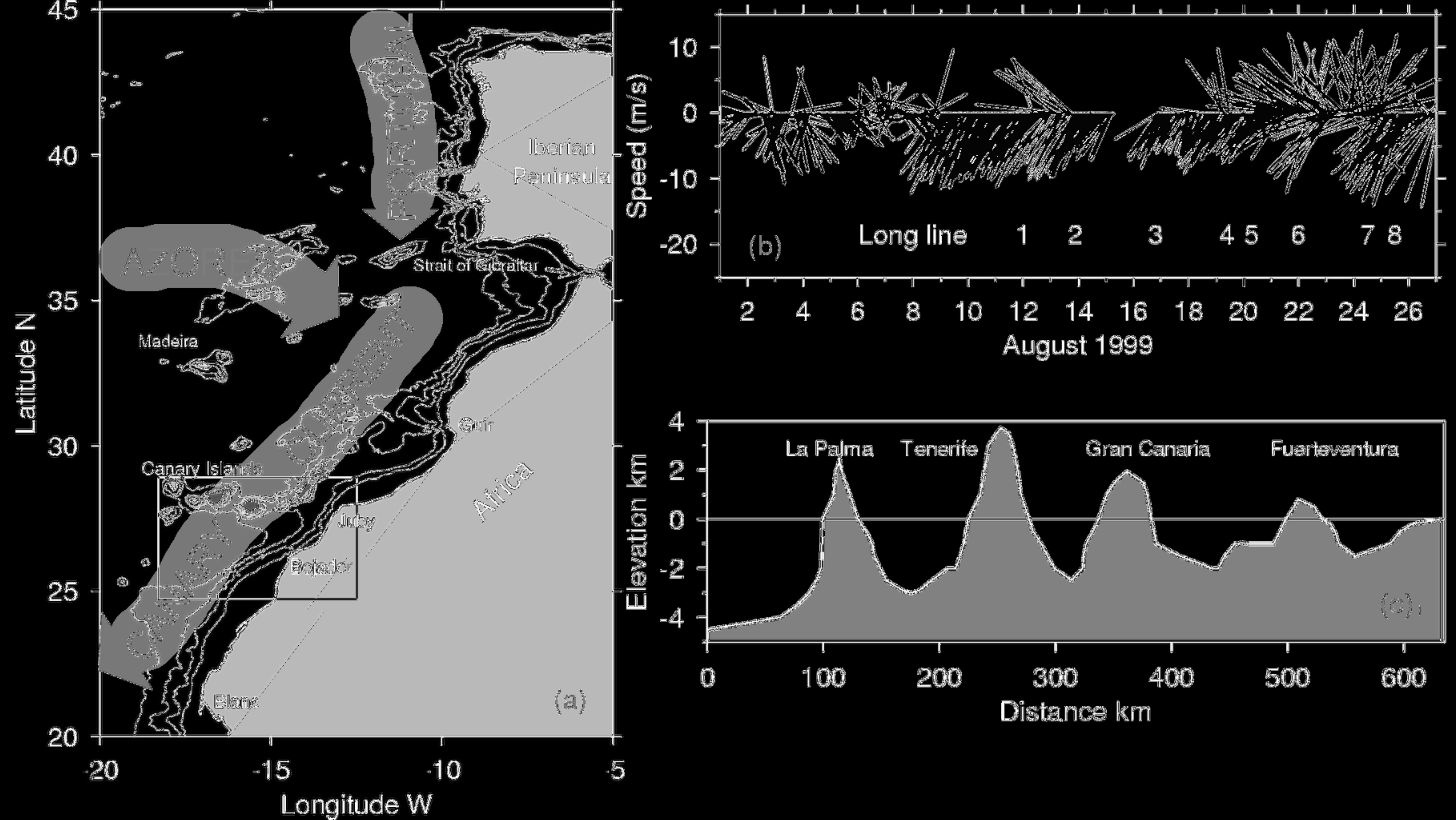




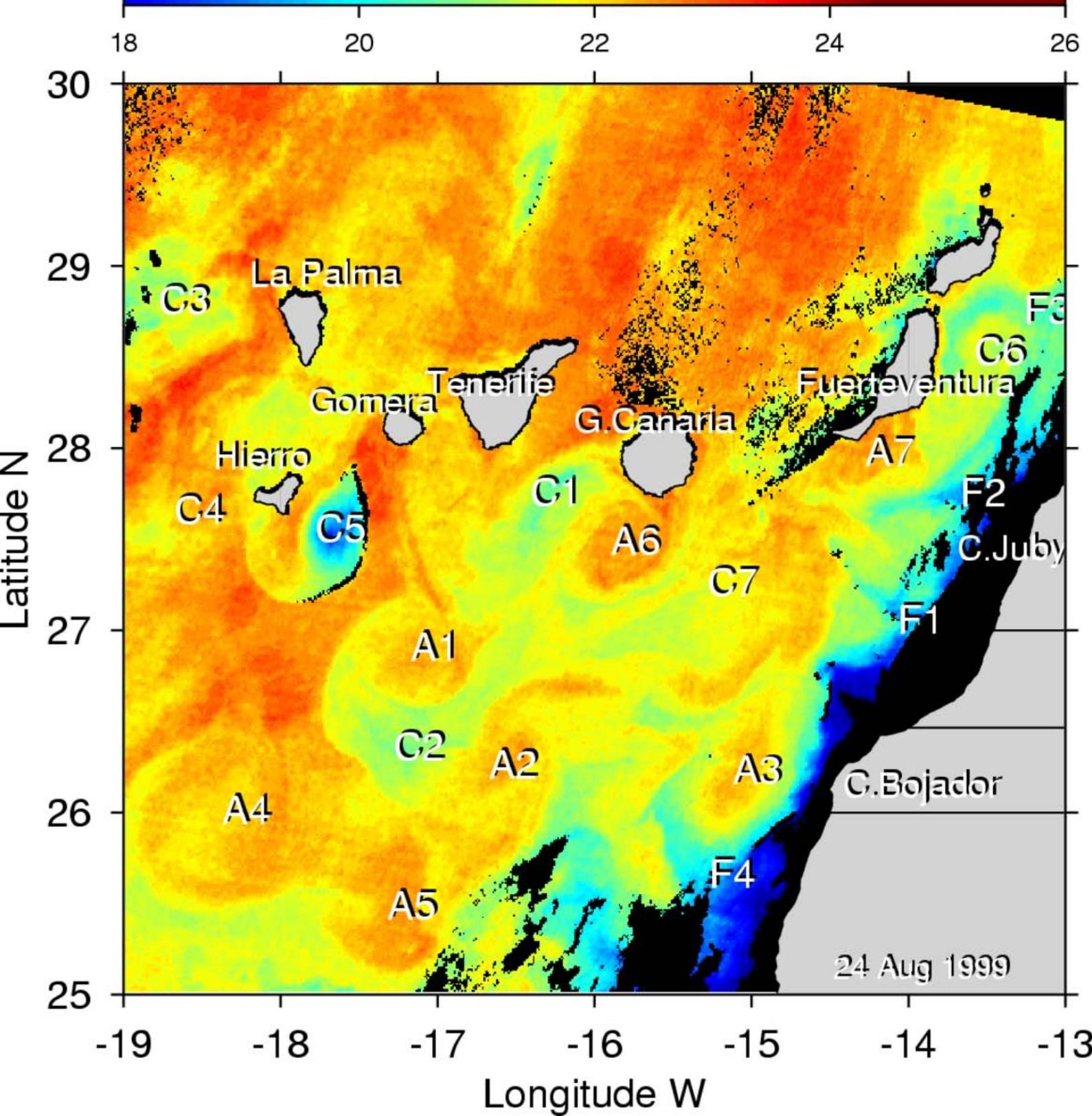




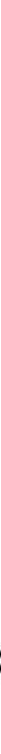



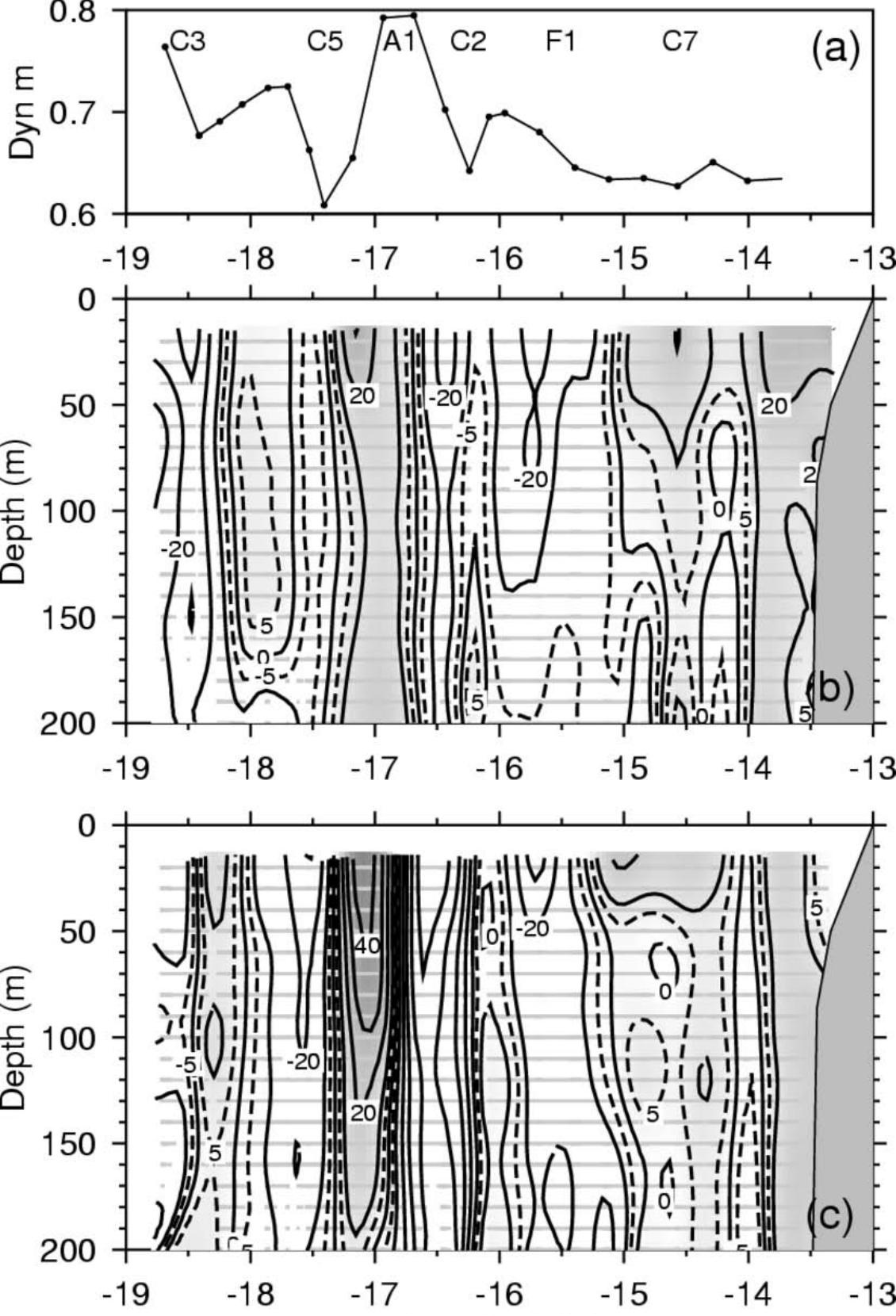


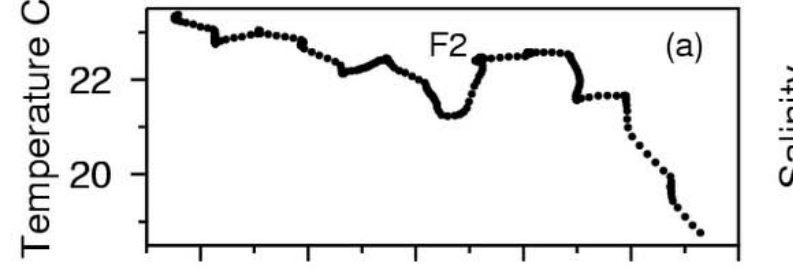

$\begin{array}{llllll}-14.2 & -14 & -13.8 & -13.6 & -13.4 & -13.2\end{array}$

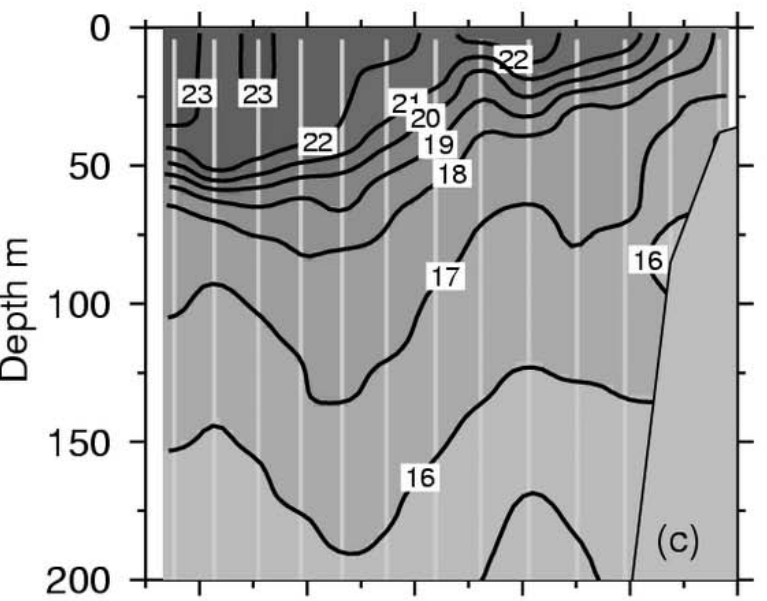

$\begin{array}{llllll}-14.2 & -14 & -13.8 & -13.6 & -13.4 & -13.2\end{array}$

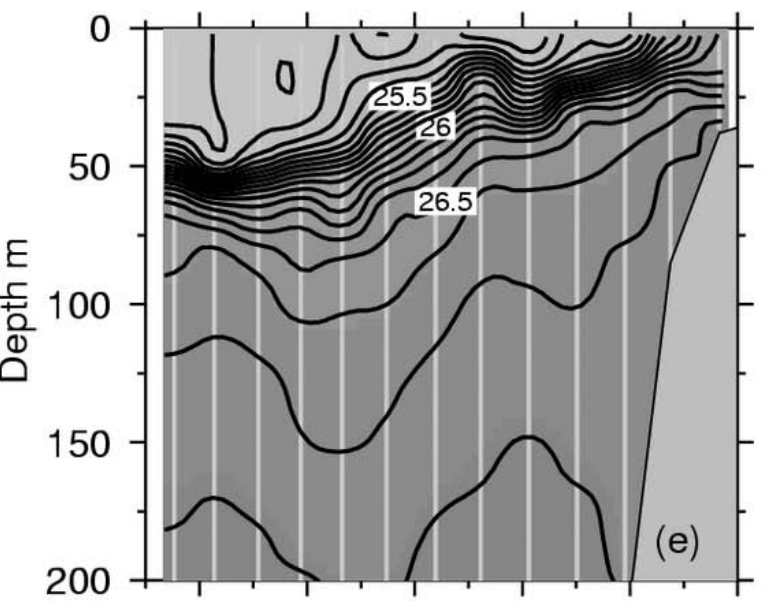

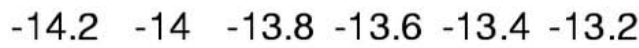
Longitude W

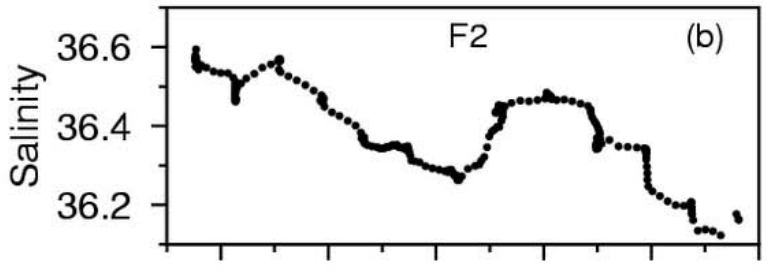

$\begin{array}{llllll}-14.2 & -14 & -13.8 & -13.6 & -13.4 & -13.2\end{array}$

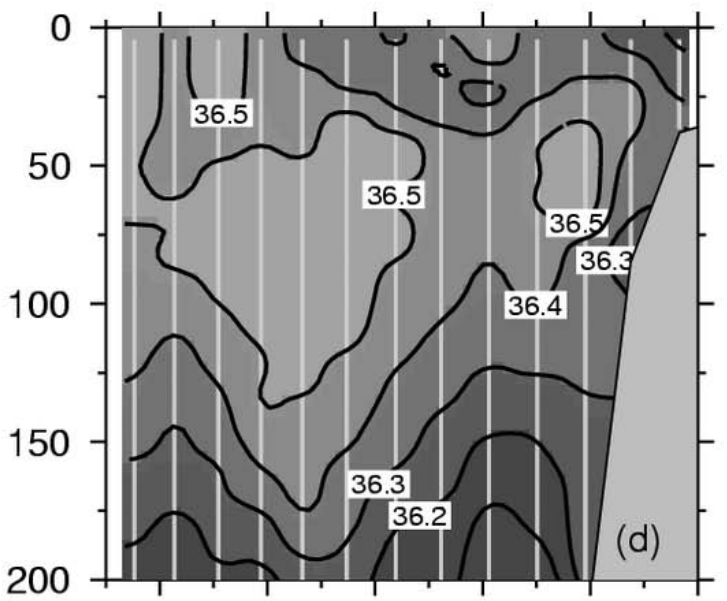

$\begin{array}{llllll}-14.2 & -14 & -13.8 & -13.6 & -13.4 & -13.2\end{array}$

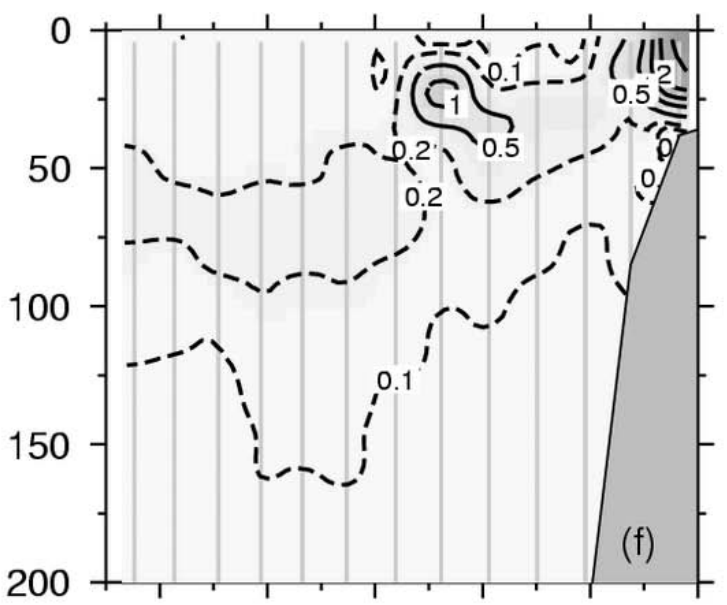

$\begin{array}{llllll}-14.2 & -14 & -13.8 & -13.6 & -13.4 & -13.2\end{array}$ Longitude $\mathrm{W}$ 


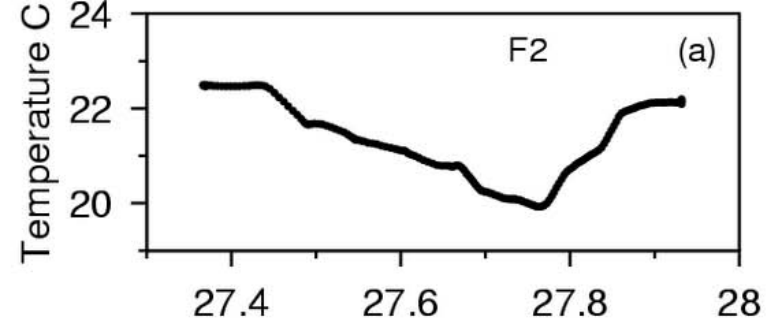

$$
\text { 政 }
$$

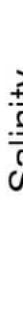

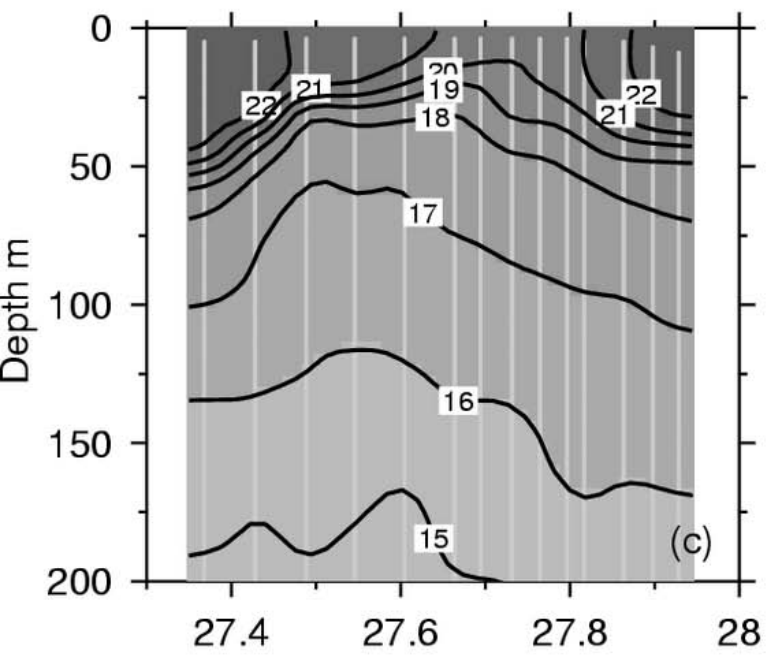
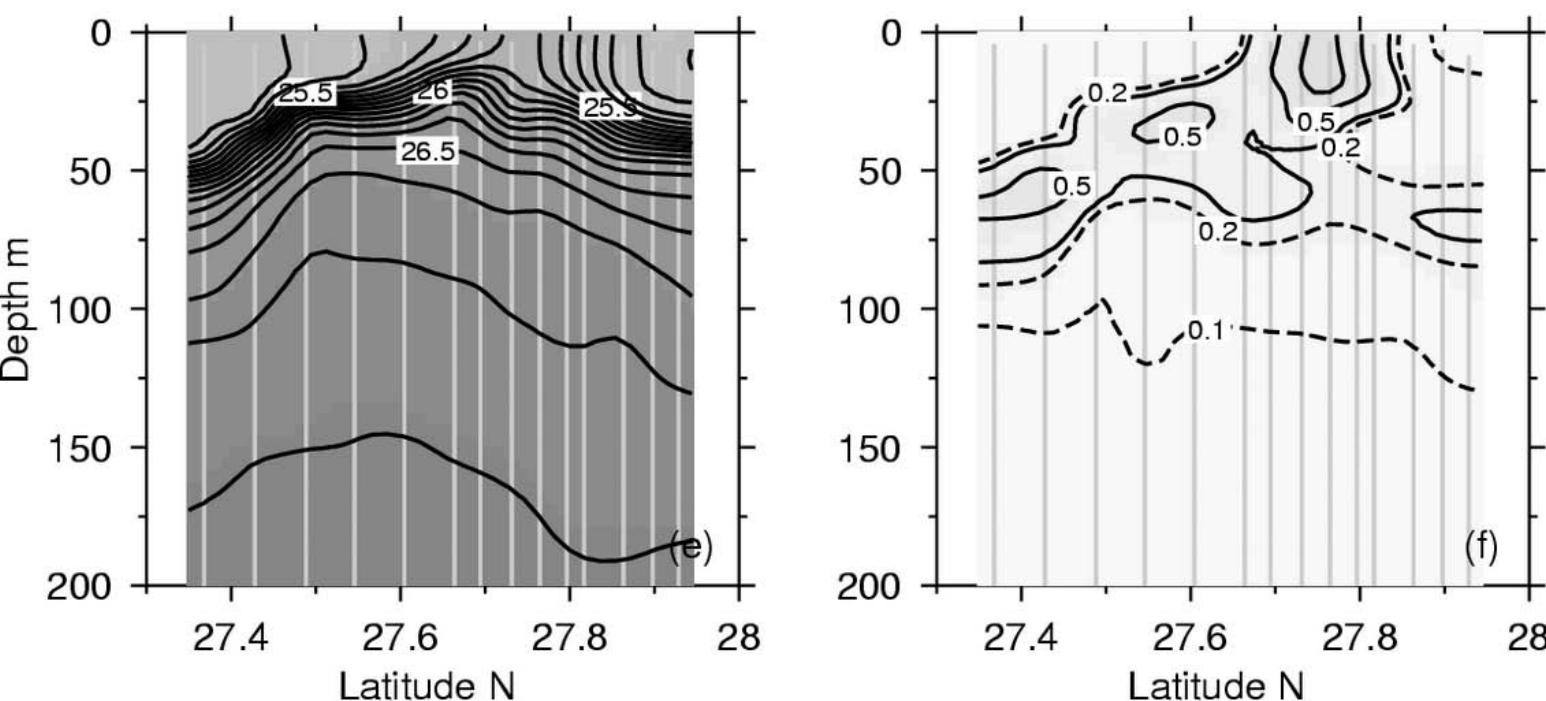

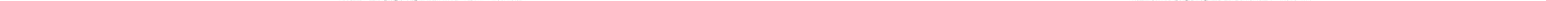


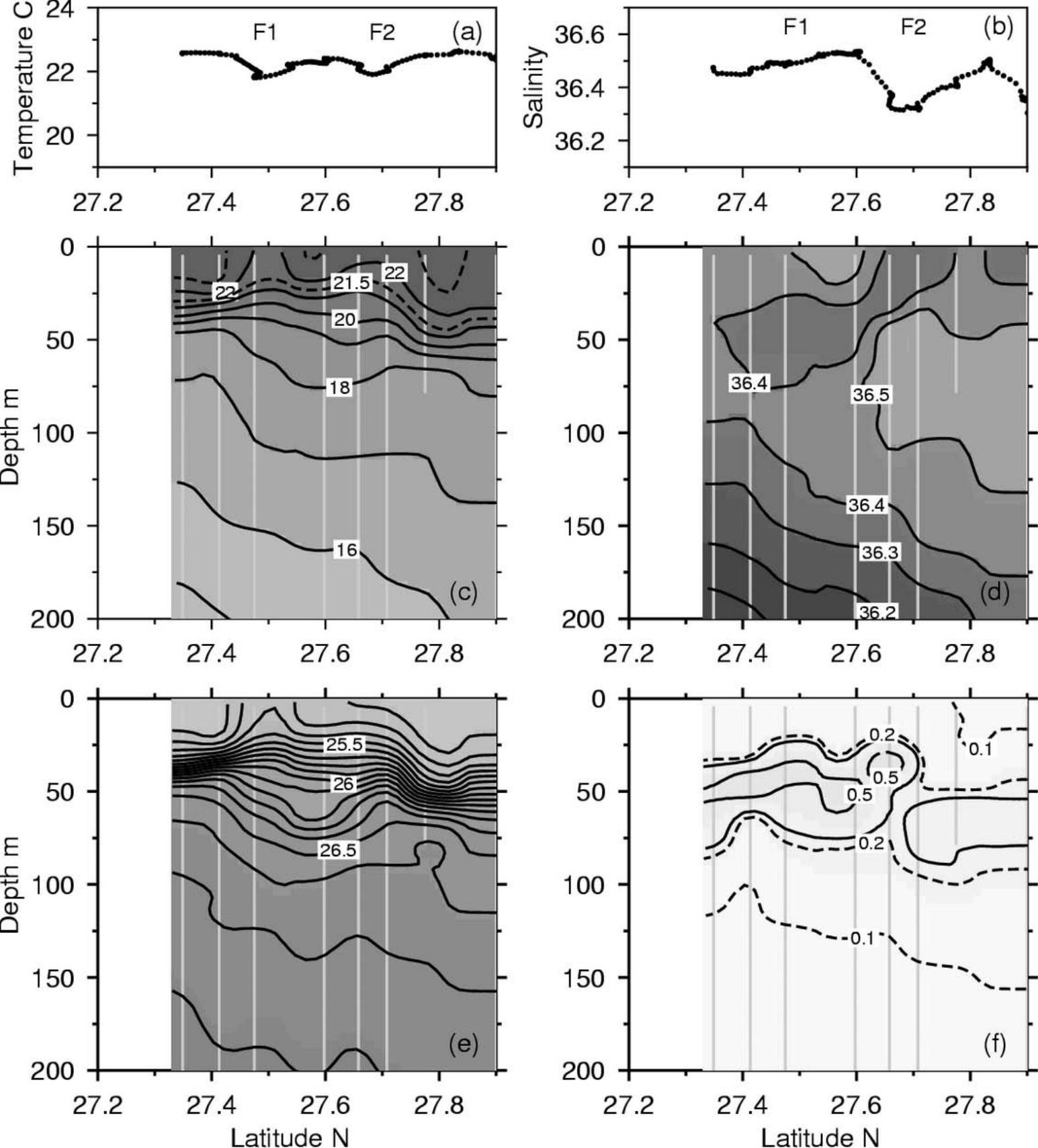




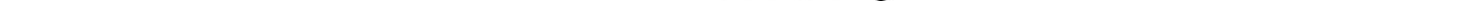

